\title{
Mutational analysis of the androgen receptor gene in two Chinese families with complete androgen insensitivity syndrome
}

\author{
SONG WANG ${ }^{1}$, HAIKUN XU ${ }^{2}$, WEI AN ${ }^{1}$, DECHUN ZHU ${ }^{1}$ and DEJUN LI ${ }^{3}$ \\ ${ }^{1}$ Department of Urology, The First Hospital of Jilin University, Changchun, Jilin 130021; \\ ${ }^{2}$ Department of Radiology, China-Japan Union Hospital of Jilin University, Changchun, Jilin 130033; \\ ${ }^{3}$ Center for Prenatal Diagnosis, The First Hospital of Jilin University, Changchun, Jilin 130021, P.R. China
}

Received January 30, 2015; Accepted March 9, 2016

DOI: $10.3892 /$ etm.2016.3234

\begin{abstract}
Androgens are essential for normal male sex differentiation and are responsible for the normal development of male secondary sexual characteristics at puberty. The physiological effects of androgens are mediated by the androgen receptor (AR). Mutations in the $A R$ gene are the most common cause of androgen insensitivity syndrome. The present study undertook a genetic analysis of the $A R$ gene in two unrelated families affected by complete androgen insensitivity syndrome (CAIS) in China. In family 1, a previously reported nonsense mutation (G-to-A; p.W751X) was identified in exon 5 of the $A R$ gene. In addition, a novel missense mutation was detected in exon 6 of the $A R$ gene from family 2; this mutation resulted in a predicted amino acid change from phenylalanine to serine at codon 804 (T-to-C; p.F804S) in the ligand-binding domain (LBD) of AR. Computer simulation of the structural changes generated by the p.F804S substitution revealed marked conformational alterations in the hydrophobic core responsible for the stability and function of the AR-LBD. In conclusion, the present study identified two mutations from two unrelated Chinese families affected by CAIS. The novel mutation (p.F804S) may provide insights into the molecular mechanism underlying CAIS. Furthermore, it expands on the number of mutational hot spots in the international AR mutation database, which may be useful in the future for prenatal diagnosis and genetic counseling.
\end{abstract}

\section{Introduction}

Androgens, such as testosterone and dihydrotestosterone, are essential for normal male sex differentiation and are responsible for the normal development of male secondary sexual

Correspondence to: Dr Dejun Li, Center for Prenatal Diagnosis, The First Hospital of Jilin University, 71 Xinmin Street, Chaoyang, Changchun, Jilin 130021, P.R. China

E-mail: lidejun@jlu.edu.cn

Key words: androgen receptor, complete androgen insensitivity syndrome, novel mutation, structural analysis characteristics at puberty (1). The physiological effects of androgens are mediated by the androgen receptor (AR), which is a nuclear transcription factor encoded by the $A R$ gene (2). The $A R$ gene, which is located on the $\mathrm{X}$ chromosome (Xq11-q12) and contains 8 exons, encodes a protein of 919 amino acids (3). Mutations in the $A R$ gene have been shown to cause androgen insensitivity syndrome (AIS), which is characterized by complete or partial resistance to the biological effects of androgens in 46,XY karyotype individuals with normal testis determination and production of age-appropriate androgen concentrations (4). AIS may be classified into mild (MAIS), partial (PAIS) or complete androgen insensitivity (CAIS), based on its phenotypic expression, which ranges from a male phenotype with isolated infertility, to ambiguous genitalia, to a completely female external phenotype (5).

CAIS, which has previously been termed testicular feminization syndrome (6), is characterized by unilateral or often bilateral inguinal hernias in prepubertal girls and with primary amenorrhea during puberty (7). The characteristic features of CAIS include a normal female phenotype, normal breast development, an absence of or sparse pubic and axillary hair, an absence of the uterus and ovaries, and a short blind-ending vagina (8). The estimated prevalence of CAIS is 1:20,000-64,000 male births (9). CAIS is typically diagnosed by clinical and laboratory findings and confirmed by the detection of a defect in the $A R$ gene. However, only a small number of patients affected by CAIS have been confirmed by $A R$ gene mutational screening in Chinese hospitals (10-12).

The present study aimed to investigate patients with CAIS from two unrelated Chinese families by screening mutations of the AR gene. Furthermore, in silico tools were used to predict the potential effect of the novel mutation on the AR protein.

\section{Patients and methods}

Families. Two unrelated families affected by CAIS were investigated in the present study. The family pedigrees and generations are illustrated in Fig. 1. In both families, there was no history of consanguineous marriage for three generations. To determine the karyotype of patients, peripheral blood lymphocytes were cultured using lymphocyte culture medium (Yishengjun; Bedi Biotechnology, Guangzhou, China) at $37^{\circ} \mathrm{C}$ 
A

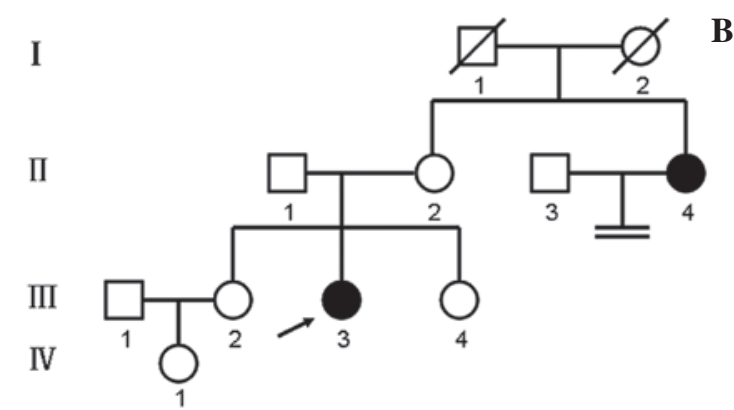

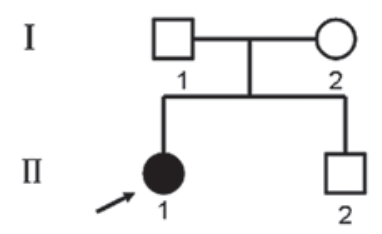

Figure 1. Pedigree analysis of the Chinese families affected with complete androgen insensitivity. (A) Family 1 and (B) family 2. Women and men are represented by circles and squares, respectively. The black circles indicate the affected individuals. The arrows indicate the proband of each family. The shapes with lines through them indicate deceased individuals.

for $72 \mathrm{~h}$. Dividing cells were arrested at metaphase stage with $20 \mu \mathrm{g} / \mathrm{ml}$ colchicin (Bedi Biotechnology) for $3 \mathrm{~h}$ prior to culture termination. Mitotic cells were incubated in a hypotonic solution $\left(0.075 \mathrm{M} \mathrm{KCl}\right.$ in $\left.\mathrm{H}_{2} \mathrm{O}\right)$ for $30 \mathrm{~min}$ at $37^{\circ} \mathrm{C}$, and then the swollen cells were fixed with Carnoy's fixative (methanol and acetic acid $=3: 1$ ). Mitotic cells were dropped onto pre-cleaned glass microscope slides and allowed to dry for 1 day at room temperature. Chromosomes were G-banded by treating the preparations with trypsin (Gibico; Thermo Fisher Scientifc, Inc., Waltham, MA, USA) followed by staining with Giemsa solution (Sigma-Aldrich, St. Louis, MO, USA), according to the manufacturer's instructions. Each patient had a 46,XY karyotype . The diagnosis of CAIS was based on the combination of a physical examination, the patient medical history, measurements of sex hormones and a gene mutational analysis. Informed written consent was obtained from all participants. The present study was approved by the ethics committee of The First Hospital of Jilin University (Changchun, China).

Patients. Family 1 is presented in Fig. 1A. The proband (III-3) was a 25-year-old female, who was referred to the Center for Prenatal Diagnosis at The First Hospital of Jilin University (Changchun, China) in January 2013 with primary amenorrhea. The patient was the second child in her family and had two normal sisters (III-2 and III-4). The maternal aunt (II-4) of the proband had a history of primary amenorrhea and infertility. At the time of examination, the proband exhibited normal female external genitalia, normal breast development and an absence of axillary and pubic hair. An ultrasound (GE LOG IQ9 device; GE Healthcare Life Sciences, Chalfont, $\mathrm{UK}$ ) revealed the absence of a uterus and ovaries, and the presence of bilateral testes-like gonads. Immunoassays detected the serum concentrations of luteinizing hormone (LH; cat. no. 1732234), follicle-stimulating hormone (FSH; cat. no. 11775863), testosterone (T; cat. no. 05200067) and estradiol ( $\mathrm{E}_{2}$; cat. no. 03000079) (all purchased from Roche Diagnostics GmbH, Mannheim, Germany). The serum hormone concentrations were as follows: LH, $52 \mathrm{mIU} / \mathrm{ml}$; FSH, $56.8 \mathrm{mIU} / \mathrm{ml}$ (both above the normal male range); testosterone (T), $25.8 \mathrm{nmol} / \mathrm{l}$ (within the normal male range); and estradiol $\left(\mathrm{E}_{2}\right), 26.35 \mathrm{pg} / \mathrm{ml}$. The normal ranges for males are as follows: LH, 1.70-8.60 mIU/ml; FSH, 1.50-12.40 mIU/ml; T, 9.9-27.8 nmol/l; and $E_{2}, 7.63-42.60 \mathrm{pg} / \mathrm{ml}$. The normal ranges for females are as follows: LH follicular phase, 2.40-12.60 mIU/ml; LH ovulation phase, 14.00-95.60 mIU/ml;
LH luteal phase, 1.00-11.40 mIU/ml; LH menopause phase, 7.70-58.50 mIU/ml; FSH follicular phase, 3.50-12.50 mIU/ml; FSH ovulation phase, 4.70-21.50 mIU/ml; FSH luteal phase, 1.70-7.70 mIU/ml; FSH menopause phase, 25.80-134.8 mIU/ml; T,0.22-2.9 nmol/1; $\mathrm{E}_{2}$ follicular phase, $12.5-166 \mathrm{pg} / \mathrm{ml} ; \mathrm{E}_{2}$ ovulation phase, 85.8-498 pg/ml; $\mathrm{E}_{2}$ luteal phase, 43.8-211 pg/ml; and $\mathrm{E}_{2}$ menopause phase, $<5-54.7 \mathrm{pg} / \mathrm{ml}$.

In family 2 (Fig. 1B), the proband (II-1) was an 18-year-old female, who was referred to the Department of Urology at The First Hospital of Jilin University in September 2012 with a right inguinal hernia and primary amenorrhea. At 3 years of age, the patient had presented with congenital bilateral inguinal hernias, which were characterized by a mass in the groin that swelled during crying. The patient had undergone a left hernia operation at the City Hospital of Yushu (Yushu, China) 8 months prior to admission, and the mass was confirmed as a testis. A further physical examination revealed that the patient had normal female external genitalia, normal breast development, sparse pubic hair and an absence of axillary hair. A gynecological examination revealed the absence of a uterus and ovaries, and the presence of a blind-ending vagina $(7.8 \mathrm{~cm}$ in depth). The serum hormone concentrations were as follows: $\mathrm{T}, 11.65 \mathrm{nmol} / \mathrm{l}$ (within the normal male range); $\mathrm{LH}, 47 \mathrm{IU} / \mathrm{ml}$; FSH, $58.89 \mathrm{mIU} / \mathrm{ml}$; and $\mathrm{E}_{2}, 22.85 \mathrm{pg} / \mathrm{ml}$.

Genetic analysis. Genomic DNA was extracted from peripheral blood leukocytes using the QIAamp DNA Blood Mini kit (51106; Qiagen GmbH, Hilden, Germany), according to the manufacturer's protocol. All eight exons and flanking intronic regions of the $A R$ gene were amplified by polymerase chain reaction (PCR) using the primers listed in Table I. The amplifications were performed using a final volume of $50 \mu \mathrm{l}$, containing $1 \mu \mathrm{l}$ genomic DNA, $25 \mu \mathrm{l} 2 \mathrm{X}$ Premix Ex Taq ${ }^{\mathrm{TM}}$ (Takara Biotechnology Co., Ltd., Dalian, China), $1 \mu$ l each of the forward and reverse primers and $22 \mu \mathrm{l}$ sterilized distilled water. The PCR conditions were as follows: $95^{\circ} \mathrm{C}$ for $5 \mathrm{~min}$, followed by 30 cycles of denaturation at $95^{\circ} \mathrm{C}$ for $30 \mathrm{sec}$, annealing at $60-65^{\circ} \mathrm{C}$ for $45 \mathrm{sec}$ and extension at $72^{\circ} \mathrm{C}$ for $30 \mathrm{sec}$, and a final extension at $72^{\circ} \mathrm{C}$ for $10 \mathrm{~min}$ (GeneAmp 9700; Applied Biosystems; Thermo Fisher Scientific, Inc.). A 5- $\mu 1$ aliquot of each PCR was loaded on a $2 \%$ agarose gel and visualized by ethidium bromide (Sigma-Aldrich) staining to confirm the presence of an appropriately sized product. Direct sequencing of amplicons from the amplification of the $A R$ gene from the proband was performed on the ABI 3730 Automated 
Table I. PCR primers used for amplifying exons and flanking intronic regions of the $A R$ gene.

\begin{tabular}{|c|c|c|c|}
\hline Primer name & Primer sequence $\left(5^{\prime}-3^{\prime}\right)$ & Product length (bp) & $\operatorname{Tm}\left({ }^{\circ} \mathrm{C}\right)$ \\
\hline AR-e1-F1 & ACAGCCTGTTGAACTCTTCTGA & 483 & 60 \\
\hline AR-e1-R1 & GCTCTGGGACGCAACCTCT & & \\
\hline AR-e1-F2 & GGTTCTCCCCAAGCCCATCGTAG & 484 & 60 \\
\hline AR-e1-R2 & GCTCCAACGCCTCCACACCC & & \\
\hline AR-e1-F3 & AAGGACAATTACTTAGGGGGCACTT & 451 & 60 \\
\hline AR-e1-R3 & CCAGAGCCAGTGGAAAGTTGTAGTA & & \\
\hline AR-e1-F4 & TTGAACTGCCGTCTACCCTGTCTCT & 531 & 60 \\
\hline AR-e1-R4 & TGGGATAGGGCACTCTGCTCACC & & \\
\hline AR-e1-F5 & CGCTTCCTCATCCTGGCACACTCTC & 410 & 60 \\
\hline AR-e1-R5 & AGGTAGGAGCCGCTAGATACCCCAG & & \\
\hline AR-e2-F & CACTAACTAACTTGAGCAATGAATA & 325 & 60 \\
\hline AR-e2-R & TAAAGGAGAAAGGGAAAGAGAAGTG & & \\
\hline AR-e3-F & CTGGAAACTCATTATCAGGTCTATC & 257 & 60 \\
\hline AR-e3-R & TCAAAGAAGAAAATCTGGTCTAAAG & & \\
\hline AR-e4-F & GTTTAGAGTCTGTGACCAGGGAG & 506 & 63 \\
\hline AR-e4-R & GGCAGAAAAGCACCAGACAT & & \\
\hline AR-e5-F & AGCATCTCTGCCCAACAGGGACTCA & 379 & 60 \\
\hline AR-e5-R & ССTCATACTGGATTGGCTGGCTGGG & & \\
\hline AR-e6-F & CTCTGGGCTTATTGTAAACTTCC & 255 & 60 \\
\hline AR-e6-R & CAAAAGTGGTCCTCTCTGAATCTCT & & \\
\hline AR-e7-F & TGTGGTCAGAAAACTTGGTG & 290 & 65 \\
\hline AR-e7-R & СТCTATCAGGCTGTTCTCCC & & \\
\hline AR-e8-F & GGAGGAAACAAAAGGCTGAAAGACC & 326 & 60 \\
\hline AR-e8-R & AACAGGCAGAAGACATCTGAAAGGG & & \\
\hline
\end{tabular}

PCR, polymerase chain reaction; AR, androgen receptor; e, exon; F, forward; R, reverse; Tm, melting temperature.

Sequencer (Applied Biosystems; Thermo Fisher Scientific, Inc.) using the BigDye ${ }^{\circledR}$ Terminator v3.1 Cycle Sequencing kit (4337455; Applied Biosystems; Thermo Fisher Scientific, Inc.). In the case of a mutation, PCR and sequencing of the DNA sample were repeated twice to confirm the finding and rule out the possibility of PCR-generated errors. Furthermore, 150 healthy male individuals were recruited as a normal control group for the study (age, 22-35 years).

Homology and structural analysis and function prediction. Upon detection of a novel mutation, the functional consequences of amino acid alterations were predicted using in silico models. Three algorithms, including Polymorphism Phenotyping (http://genetics.bwh.harvard. edu/pph2/; version 2.2.2), Scale Invariant Feature Transform (http://sift.jcvi.org/; version 4.0) and Protein Analysis Through Evolutionary Relationships (http://www.pantherdb. org/tools/csnpScoreForm.jsp; version 6.1), were used to predict the functional consequences of amino acid substitutions.

For homology studies, the human $A R$ sequence was compared with corresponding mammalian protein sequences from the Ensemble database (http://www.ensembl.org/index. html) using the ClustalW multiple sequence alignment tool (http://www.ebi.ac.uk/Tools/msa/clustalw2/.) The structure of the mutant AR protein was predicted using the resolved three dimensional structure of human AR (Protein Data Bank accession \#2AM9) as a template. Molecular modeling was performed using the SWISS-MODEL web-server program (http://swissmodel.expasy.org/). The model images were examined and edited using PyMOL (https://www.pymol.org/l; version 1.5$)$.

\section{Results}

Genetic analysis of the AR gene. In family 1, a direct sequencing analysis of the proband (III-3) detected a homozygous G-to-A substitution in exon 5 of the $A R$ gene, which led to the replacement of a tryptophan (W) codon (TGG) with a termination (X) codon (TGA) at amino acid position 751 (p.W751X). The mother of the proband (II-2) was a heterozygous carrier of the p.W751X mutation, and II-4 harbored the same mutation as the proband, whereas the elder sister of the proband (III-2) had normal alleles at the $A R$ gene (Fig. 2A).

A T-to-C substitution at codon 804 (TTC-TCC) in exon 6 of the $A R$ gene was identified in the proband (II-1) from family 2 ; this mutation was predicted to result in an amino acid change from phenylalanine $(\mathrm{F})$ to serine $(\mathrm{S})$ at amino acid position 804 (p.F804S) in the ligand-binding domain (LBD) of the AR protein. However, a molecular analysis of the proband's 
A

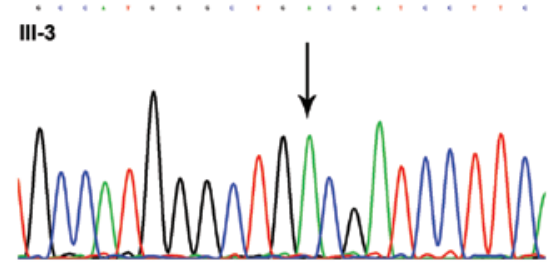

II-2

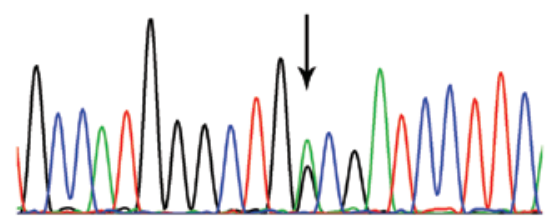

B

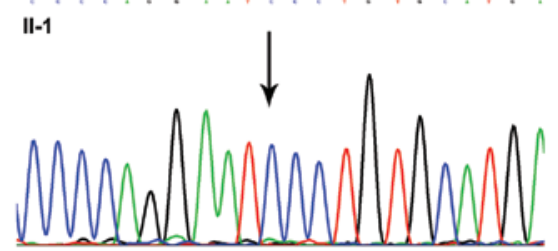

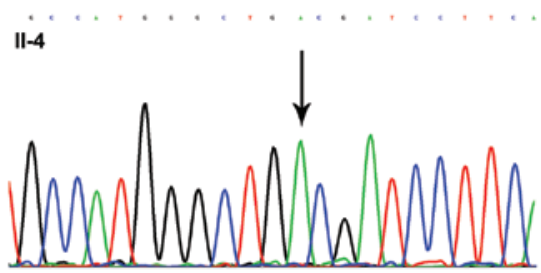

III-2
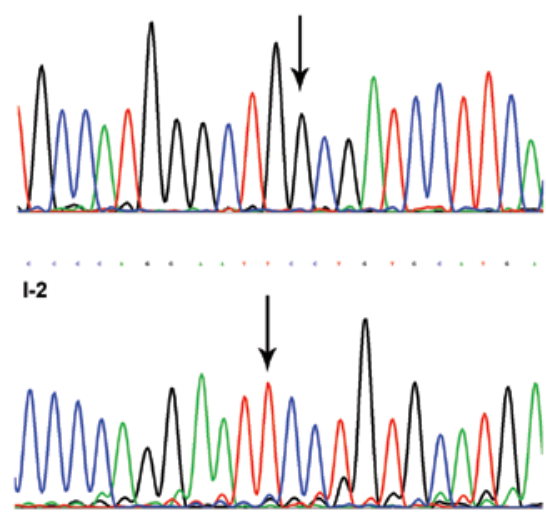

Figure 2. Mutation analysis of the androgen receptor gene in the probands and their relatives. The location of the mutation site is indicated by the black arrow. (A) In family 1, the proband (III-3) and her maternal aunt (II-4) harbored the homozygous G-to-A substitution in exon 5, the mother of the proband (II-2) was a heterozygous carrier, and the elder sister of the proband (III-2) was normal. (B) In family 2, the proband (II-1) harbored the homozygous T-to-C substitution in exon 6, whereas her mother (I-2) was normal at this site.

\begin{tabular}{ll} 
Homo sapiens & \multicolumn{1}{c}{$\mathbf{8 0 4}$} \\
Pan troglodytes & SQEFGWLQITPQEFLCMKALLLFSIIPVDG \\
Macaca mulatta & SQEFGWLQITPQEFLCMKALLLFSIIPVDG \\
Oryctolagus cuniculus & SQEFGWLQITPQEFLCMKALLLFSIIPVDG \\
Canis familiaris & SQEFGWLQITPQEFLCMKALLLFSIIPVDG \\
Sus scrofa & SQEFGWLQITPQEFLCMKALLLFSIIPVDG \\
Rattus norvegicus & SQEFGWLQITPQEFLCMKALLLFSIIPVDG \\
Mus musculus & SQEFGWLQITPQEFLCMKALLLFSIIPVDG
\end{tabular}

Figure 3. Multiple sequence alignment of androgen receptor gene orthologs around codon 804 . Codon 804 was highly conserved across various vertebrate species.

mother (I-2) revealed normal alleles, and this mutation was absent in all of the 150 normal control subjects (Fig. 2B).

Functional and structural prediction of the AR protein with the novel mutation. To the best of our knowledge, the p.F804S mutation has not previously been described, and was thus analyzed in silico. All three in silico algorithms predicted that the substitution of $\mathrm{F}$ with $\mathrm{S}$ would affect the function of the AR protein (Table II). F804 is a highly conserved residue, as demonstrated when comparing the human AR protein sequence to other mammalian AR proteins by multiple sequence alignments (Fig. 3).

The structural analysis demonstrated that, in the wild-type AR protein, F804 was located in a hydrophobic cage consisting of F747, W751, F794, leucine 805 and lysine 808. At the same time, the aromatic side chains of F804 and W751 were aligned in an off-centered parallel orientation to form a $\pi$-stacking structure (Fig. 4A). However, in the mutant AR protein, the structural analysis by modeling revealed that, as compared with the wild-type F804 reside, S804 did not form a hydrophobic interaction with F747, and instead formed an intramolecular hydrophobic interaction with isoleucine (I) 799. In addition, S804 was extended from the hydrophobic cage and established a hydrogen bond with the backbone carbonyl group of threonine (T) 800 (Fig. 4B).

\section{Discussion}

AIS is the most common cause of male pseudohermaphroditism, and is considered a member of the 46,XY disorders of sex development (13). AIS is an X-linked inherited disorder caused by mutations in the $A R$ gene (14). The AR is an intracellular transcription factor belonging to the nuclear receptor superfamily. In the absence of a ligand, the AR protein is located in the cytoplasm; however, androgen binding induces the AR to adopt its trans-conformation, permitting 
Table II. Prediction of the effect of the p.F804S mutation on the function of the androgen receptor protein using three algorithms.

\begin{tabular}{ll} 
Algorithm & \multicolumn{1}{c}{ Prediction } \\
\hline PolyPhen & $\begin{array}{l}\text { Probably damaging } \\
\text { Score }=1.000 \text { (sensitivity, 0.00; specificity, 1.00) }\end{array}$ \\
SIFT & $\begin{array}{l}\text { Affect protein function } \\
\text { SIFT score }=0.00\end{array}$ \\
PANTHER & $\begin{array}{l}\text { Probability of deleterious effect }=0.79 \\
\text { subPSEC score }=-4.31\end{array}$
\end{tabular}

F, phenylalanine; S, serine; PolyPhen, Polymorphism Phenotyping; SIFT, Scale Invariant Feature Transform; PANTHER, Protein Analysis Through Evolutionary Relationships; subPSEC, substitution position-specific evolutionary conservation.

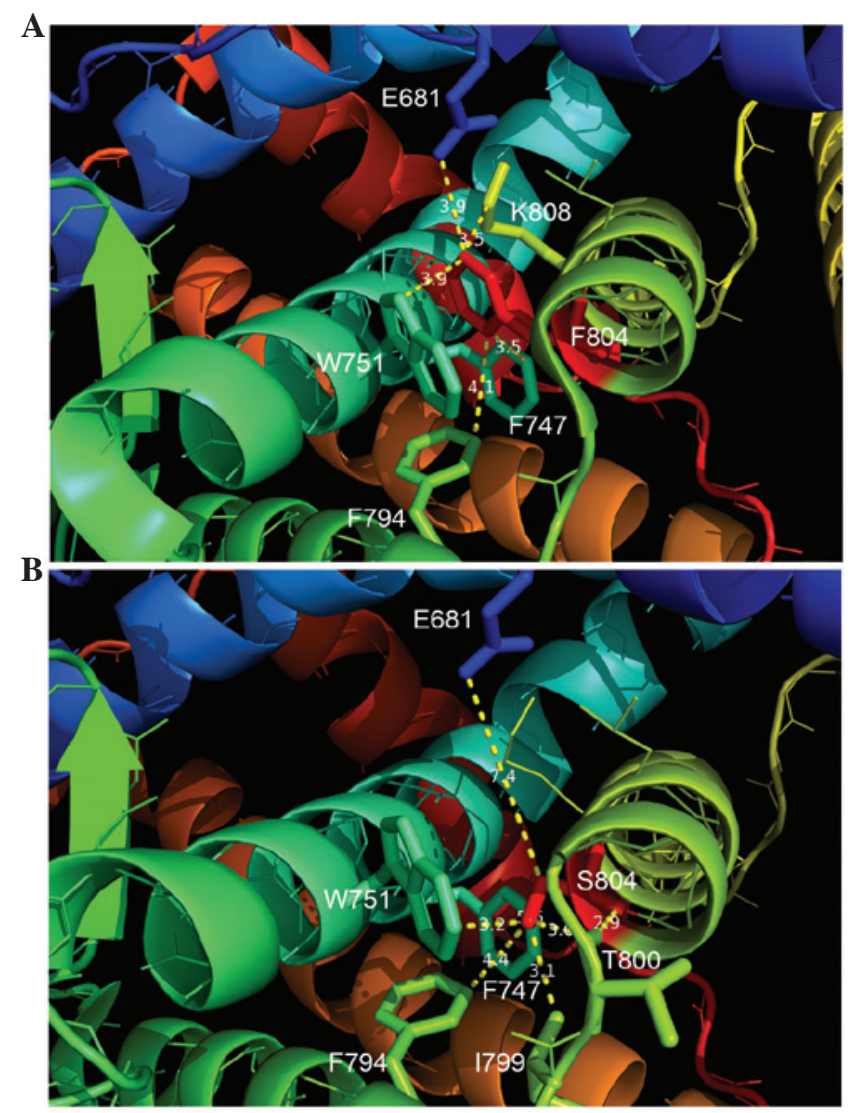

Figure 4. Pymol results of the p.F804S mutation in family 2. The numbers on the dotted lines are the estimated distances $(\AA)$ for contacts with the F804 or S804 residues. (A) The structural analysis of the F804 residue in the wild-type AR-LBD.(B) The structural analysis of the S804 residue in the mutant AR-LBD. F, phenylalanine; S, serine; W, tryptophan; E, glutamic acid; T, threonine; I, isoleucine; $\mathrm{K}$, lysine; AR-LBD, androgen receptor-ligand binding domain.

its translocation into the nucleus and direct interaction with its target genes in order to regulate their transcription and initiate a series of molecular events required for male sex differentiation (15). Consistent with all nuclear receptors, the AR consists of three major functional domains, as follows: i) The N-terminal transactivational domain, which is encoded by exon 1 and is involved in the transcriptional activation of target genes; ii) the DNA-binding domain, which is encoded by exons 2 and 3 and contains two zinc finger motifs; and iii) the C-terminal LBD, which is encoded by exons 4-8 and is involved in dimerization and transcriptional activation (16). To date, $>800$ different mutations, associated with various forms of AIS and scattered throughout the AR gene, have been reported worldwide (17).

The present study screened the entire coding and intron-exon regions of the $A R$ gene in two unrelated Chinese families with CAIS. In family 1 , one previously reported mutation (p.W751X) in exon 5 of the $A R$ gene was identified in two CAIS individuals and one unaffected carrier. In family 2 , a novel mutation (p.F804S) was identified in the LBD of AR, and the consequence of this amino acid substitution was predicted using bioinformatics.

In family 1, the p.W751X mutation identified in the proband (III-3) was inherited from the unaffected mother (II-2), who was a normal heterozygous carrier of this mutation. In addition, the aunt of the proband (II-4) was positive for the p.W751X mutation, which may have accounted for her history of primary amenorrhea and infertility. Conversely, the elder sister of the proband had the wild-type allele, and the younger sister (III-4) of the proband may have been an unaffected carrier of the p.W751X mutation, although this individual was not analyzed due to lack of parental consent.

Yaegashi et al (18) initially reported the p.W751X mutation in a Japanese patient who presented with the CAIS phenotype and had a 47,XXY karyotype in 1999. They identified two nonsense mutations (p.G641X and p.W751X) in this patient, and a cultured genital skin fibroblast study demonstrated that these mutations eliminated the ligand binding capacity of AR (18). Furthermore, they also reported that the p.G641X mutation alone was able to cause the CAIS phenotype and eliminate the androgen binding capacity (18). Conversely, Köhler et al (19) detected the p.W751X mutation in a patient with PAIS from Italy. In the present study, the p.W751X mutation was identified in a CAIS patient with a 46,XY karyotype. Thus, the same mutation in the $A R$ gene may cause different clinical manifestations in patients from different populations.

In family 2, the proband (II-1) was affected by CAIS, which presented as a bilateral inguinal hernia in childhood and primary amenorrhea during puberty. DNA sequencing identified the novel p.F804S mutation in the proband (II-1), which was not detected in the mother of the proband (I-2). These results suggested that the mutation was either de novo or the result of a possible gametic mosaicism. Furthermore, the mutation was absent in the genomes of 150 normal control individuals, which excluded the possibility of this alteration being the result of a single nucleotide polymorphism. To the best of our knowledge, the p.F804S mutation has not previously been reported, although two previously reported mutations in the same codon involving different nucleotides (TTC-CTC, p.F804l) and (TTC-ATC, p.F804L) were also associated with CAIS $(20,21)$. Considering that all three identified mutations at F804 have been associated with CAIS, the present study compared the human AR sequence with the corresponding mammalian protein sequences using ClustalW. F804 was shown to be part of highly conserved amino acid residues in 
the AR-LBD; thus suggesting that this residue is important for the function of the protein. In addition, all three in silico algorithms predicted that the p.F804S mutation would affect protein function.

In a previous study, X-ray crystallography demonstrated that the three-dimensional structure of the AR-LBD consisted of $12 \alpha$-helices (H), which folded into a three-layered sandwich $(22,23)$. The outer leaves of this sandwich, which consisted of $\mathrm{H} 1 / 2$ and 3 on one side and $\mathrm{H} 6$, 7 and 10/11 on the other, enveloped a hydrophobic core. H4/5, 8 and 9 formed one-half of this hydrophobic core, whereas the second half of the core was an open ligand-binding pocket, which, in the presence of androgen, was closed by repositioning of the terminal H12 (24). F804 was shown to be located in H8, which was the central helix in the hydrophobic core of the AR-LBD. In the present study, a structural analysis demonstrated that, in the wild-type AR-LBD, F804 interacted with E681 in H1 and F794 in H7 from the outer layer of the sandwich, and with F747 and W751 in H5 from the hydrophobic core. Furthermore, F804 was shown to be inserted into a hydrophobic cage which consisted of F747, W751, F794, L805 and K808. In addition, the aromatic side chains of F804 and W751 were aligned in an off-centered parallel orientation to form a $\pi$-stacking structure. These results suggested that F804 is a focal residue that anchors the outer layer (H1/2 and 7) of the AR-LBD to its hydrophobic core (H5 and 8). However, upon substitution with the non-polar, aromatic $\mathrm{F}$ with a polar amino $\mathrm{S}$, the modeling revealed that the S804 in the mutant AR-LBD mainly eradicated the hydrophobic interaction with F747 from H5, and lost interaction with E681 on H1, and established a new interaction between I799 and H7. Furthermore, due to the polar nature of S, S804 was extended from the hydrophobic core, which enabled it to form a hydrogen bond with the backbone carbonyl group of T800. Therefore, it may be hypothesized that the loss of the interaction between F747 and E681 in H1 may have altered the stability of the AR-LBD, such that the LBD was prone to misfolding. Furthermore, suppression of the hydrophobic interaction with residue F747 may have destabilized the interaction between $\mathrm{H} 5$ and $\mathrm{H} 8$, which in the wild-type protein forms an important hydrophobic core that maintains the AR binding capacity.

In conclusion, the present study identified two mutations in two unrelated Chinese families with CAIS by molecular screening of the $A R$ gene. The novel missense mutation (p.F804S) identified in family 2 may provide insights into the molecular mechanism underlying CAIS. In addition, the novel mutation expanded in the $A R$ database may aid in the identification of mutational hot spots, which may be useful in prenatal diagnosis and genetic counseling.

\section{Acknowledgements}

The authors of the present study would like to thank the study participants for their involvement in this study.

\section{References}

1. Gottlieb B, Lombroso R, Beitel LK and Trifiro MA: Molecular pathology of the androgen receptor in male (in)fertility. Reprod Biomed Online 10: 42-48, 2005.
2. Rosa S, Biason-Lauber A, Mongan NP, Navratil F and Schoenle EJ: Complete androgen insensitivity syndrome caused by a novel mutation in the ligand-binding domain of the androgen receptor: Functional characterization. J Clin Endocrinol Metab 87: 4378-4382, 2002.

3. Lubahn DB, Joseph DR, Sullivan PM, Willard HF, French FS and Wilson EM: Cloning of human androgen receptor complementary DNA and localization to the X chromosome. Science 240: 327-330, 1988.

4. Hughes IA, Davies JD, Bunch TI, Pasterski V, Mastroyannopoulou K and MacDougall J: Androgen insensitivity syndrome. Lancet 380: 1419-1428, 2012.

5. Brinkmann AO: Molecular basis of androgen insensiticty. Mol Cell Endocrinol 179: 105-109, 2001.

6. Morris JM: The syndrome of testicular feminization in male pseudohermaphrodites. Am J Obstet Gynecol 65: 1192-1211, 1953.

7. Decaestecker K, Philibert P,De Baere E,Hoebeke P, Kaufman JM, Sultan C and T'Sjoen G: A novel mutation c.118delA in exon 1 of the androgen receptor gene resulting in complete androgen insensitivity syndrome within a large family. Fertil Steril 89: 1260.e3-e7, 2008.

8. Raicu F, Giuliani R, Gatta V, Palka C, Franchi PG, Lelli-Chiesa P, Tumini S and Stuppia L: Novel mutation in the ligand-binding domain of the androgen receptor gene (1790p) associated with complete androgen insensitivity syndrome. Asian J Androl 10: 687-691, 2008.

9. Ahmed SF, Cheng A, Dovey L, Hawkins JR, Martin H, Rowland J, Shimura N, Tait AD and Hughes IA: Phenotypic features, androgen receptor binding, and mutational analysis in 278 clinical cases reported as androgen insensitivity syndrome. J Clin Endocrinol Metab 85: 658-665, 2000.

10. Sun S, Luo F, Zhou Z and Wu W: A novel androgen receptor gene mutation in a Chinese patient with complete androgen insensitivity syndrome. Eur J Obstet Gynecol Reprod Biol 153: $173-175,2010$.

11. Li BK, Ding Q, Wan XD and Wang X: Clinical and genetic characterization of complete androgen insensitivity syndrome in a Chinese family. Genet Mol Res 10: 1022-1031, 2011.

12. Cong P, Ye Y, Wang Y, Lu L, Yong J, Yu P, Joseph KK, Jin F and Qi M: A large deletion/insertion-induced frameshift mutation of the androgen receptor gene in a family with a familial complete androgen insensitivity syndrome. Gene 500: 220-223, 2012.

13. Hughes IA: Disorders of sex development: A new definition and classification. Best Pract Res Clin Endocrinol Metab 22: 119-134, 2008.

14. Brown TR1, Lubahn DB, Wilson EM, Joseph DR, French FS and Migeon CJ: Deletion of the steroid-binding domain of the human androgen receptor gene in one family with complete androgen insensitivity syndrome: Evidence for further genetic heterogeneity in this syndrome. Proc Natl Acad Sci USA 85: 8151-8155, 1988.

15. Sultan C, Paris F, Terouanne B, Balaguer P, Georget V, Poujol N, Jeandel C, Lumbroso S and Nicolas JC: Disorders linked to insufficient androgen action in male children. Hum Reprod Update 7: 314-322, 2001.

16. Brinkmann AO, Faber PW, van Rooij HC, Kuiper GG, Ris C, Klaassen P, van der Korput JA, Voorhorst MM, van Laar JH, Mulder E, et al: The human androgen receptor: Domain structure, genomic organization and regulation of expression. J Steroid Biochem 34: 307-310, 1989.

17. Gottlieb B, Beitel LK, Nadarajah A, Paliouras M and Trifiro M: The androgen receptor gene mutations database: 2012 update. Hum Mutat 33: 887-894, 2012.

18. Yaegashi N, Uehara S, Senoo M, Sato J, Fujiwara J, Funato T, Sasaki T and Yajima A: Point mutations in the steroid-binding domain of the androgen receptor gene of five Japanese patients with androgen insensitivity syndrome. Tohoku J Exp Med 187: 263-272, 1999.

19. Köhler B, Lumbroso S, Leger J, Audran F, Grau ES, Kurtz F, Pinto G, Salerno M, Semitcheva T, Czernichow P and Sultan C: Androgen insensitivity syndrome: Somatic mosaicism of the androgen receptor in seven families and consequences for sex assignment and genetic counseling. J Clin Endocrinol Metab 90: 106-111, 2005.

20. Gad YZ, Mazen I, Lumbroso S, Temtamy SA and Sultan C: A novel point mutation of the androgen receptor (F804L) in an Egyptian newborn with complete androgen insensitivity associated with congenital glaucoma and hypertrophic pyloric stenosis. Clin Genet 63: 59-63, 2003. 
21. Cheikhelard A, Morel Y, Thibaud E, Lortat-Jacob S, Jaubert F, Polak $M$ and Nihoul-Fekete C: Long-term followup and comparison between genotype and phenotype in 29 cases of complete androgen insensitivity syndrome. J Urol 180: 1496-1501, 2008.

22. Matias PM, Donner P, Coelho R, Thomaz M, Peixoto C, Macedo S, Otto N, Joschko S, Scholz P, Wegg A, et al: Structural evidence for ligand specificity in the binding domain of the human androgen receptor. Implications for pathogenic gene mutations. J Biol Chem 275: 26164-26171, 2000.
23. Sack JS, Kish KF, Wang C, Attar RM, Kiefer SE, An Y, Wu GY, Scheffler JE, Salvati ME, Krystek SR Jr, et al: Crystallographic structures of the ligand-binding domains of the androgen receptor and its T877A mutant complexed with the natural agonist dihydrotestosterone. Proc Natl Acad Sci USA 98: 4904-4909, 2001.

24. Ong YC, Kolatkar PR and Yong EL: Androgen receptor mutations causing human androgen insensitivity syndromes show a key role of residue M807 in Helix 8-Helix 10 interactions and in receptor ligand-binding domain stability. Mol Hum Reprod 8: 101-108, 2002 . 